\title{
New Treatment of Patients with Severe Sepsis - report from a press briefing
}

Karl Øyri, RN, CCN, MNSc, Nurse Manager and Researcher, The Interventional Centre, Rikshospitalet University Hospital, Oslo, Norway.

E-mail: karl.oyri@deltadigital.no

Key words: critical care nursing randomised controlled trial RCT septic shock severe sepsis

\section{SUMMARY \\ * This article reports on the press briefing Sepsis: Early Treatment and Survival, which was presented at the 16th Annual European Society of Intensive Care Medicine Congress held in Amsterdam, The Netherlands in October 2003 \\ * An overview of sepsis and its pathophysiology is given \\ * The medical treatment of sepsis and the clinical conse quences of using Activated Protein $\mathrm{C}$ as a treatment for sepsis are outlined \\ * Implications for critical care nurses are discussed}

\section{INTRODUCTION}

During the 16th Annual European Society of Intensive Care Medicine Congress (ESICM) in Amsterdam at the beginning of October 2003, the pharmaceutical company 'Lilly' invited journalists from various European healthcare journals to a press briefing with the title Sepsis: Early Treatment and Improved Survival. I had the pleasure of representing CONNECT and getting my expenses covered in return for writing about this event. This article is my report of the material presented during the afternoon meeting, with some additional discussion and references to literature. Invited by Lilly, presenters at the meeting were Dr Mitchell Levy (US), Dr Julian Bion (UK), Dr Pierre-Francois Laterre (Belgium) and Kathleen Vollman, RN (US).

\section{HARD FACTS ABOUT SEPSIS}

Sepsis is well known among healthcare professionals as a major problem with severe complications and is one of the most common causes of death in the ICU patient population. This knowledge is not shared by the public, and raises the need for us to focus on the problem and put sepsis on the agenda. Worldwide, an estimated 1,400 patients die every day from sepsis (Bone 1992) and it causes up to 135,000 European ICU deaths annually (Davies et al. 2001). The annual incidence of severe sepsis is indicated as three cases per 1,000 population or over 18 million cases worldwide, which is equivalent to the entire populations of Denmark, Finland, Ireland and Norway added together (Angus et al. 2001).

Critical care nurses are among the healthcare professionals that witness sepsis in everyday practice, and hold a key position in the battle against the dangerous and often rapid development of infection and complex physiological responses related to severe septic disease. As the average age of ICU patients and the general population is slowly increasing, the incidence of sepsis is expected to double in the next 50 years.

Sepsis is defined as 'caused by the body's overwhelming systemic response to infection characterised by systemic inflammation, activated microvascular coagulation (blood clotting) and altered fibrinolysis ('clot busting'). Sepsis often results in acute organ dysfunction and frequently death' (Bone 1992).

In European ICUs, severe sepsis is associated with deaths on a scale similar to that for lung cancer, breast cancer or colon cancer every year (Davies et al. 2001). In the European Union alone, the annual cost of treating patients with severe sepsis in the ICU is estimated to be up to 7.6 billion EUR (Davies et al. 2001). CONNECT wants to highlight the problems of sepsis, and provide information to critical care nurses to prepare them for the challenges they face in the battle against sepsis, the silent killer in the ICU. Knowledge is a key factor, and can be used in a positive way to save lives. Critical care nurses can use this article to update their knowledge and implement evidence-based nursing practice.

\section{Pathophysiology in Severe Sepsis}

While the exact cause of sepsis is unknown, increasing evidence suggests that it is associated with widespread inflammation, coagulation and suppression of fibrinolysis - which is thought to occur when chemical signals in the immune system go awry. Figure 1 shows the complex cascade of physiological reactions related to severe sepsis development.

Severe sepsis involves changes in coagulation, inflammation and the fibrinolytic systems. The result is uncontrolled systemic inflammation often without a specific location or defined focus, and leads to excessive and exaggerated coagulation and ineffective fibrinolysis. Organ perfusion is reduced and tissue oxygenation threatened, even if cardiac output is adequate, due to a hyper-dynamic state with regional and peripheral vasoconstriction associated with a decreased systemic vascular resistance. Initially the oxygen saturation in the central venous blood $\mathrm{SvO}_{2}$ is higher than normal and later becomes subnormal due to an increased compensatory metabolism. Other clinical markers can be altered: 


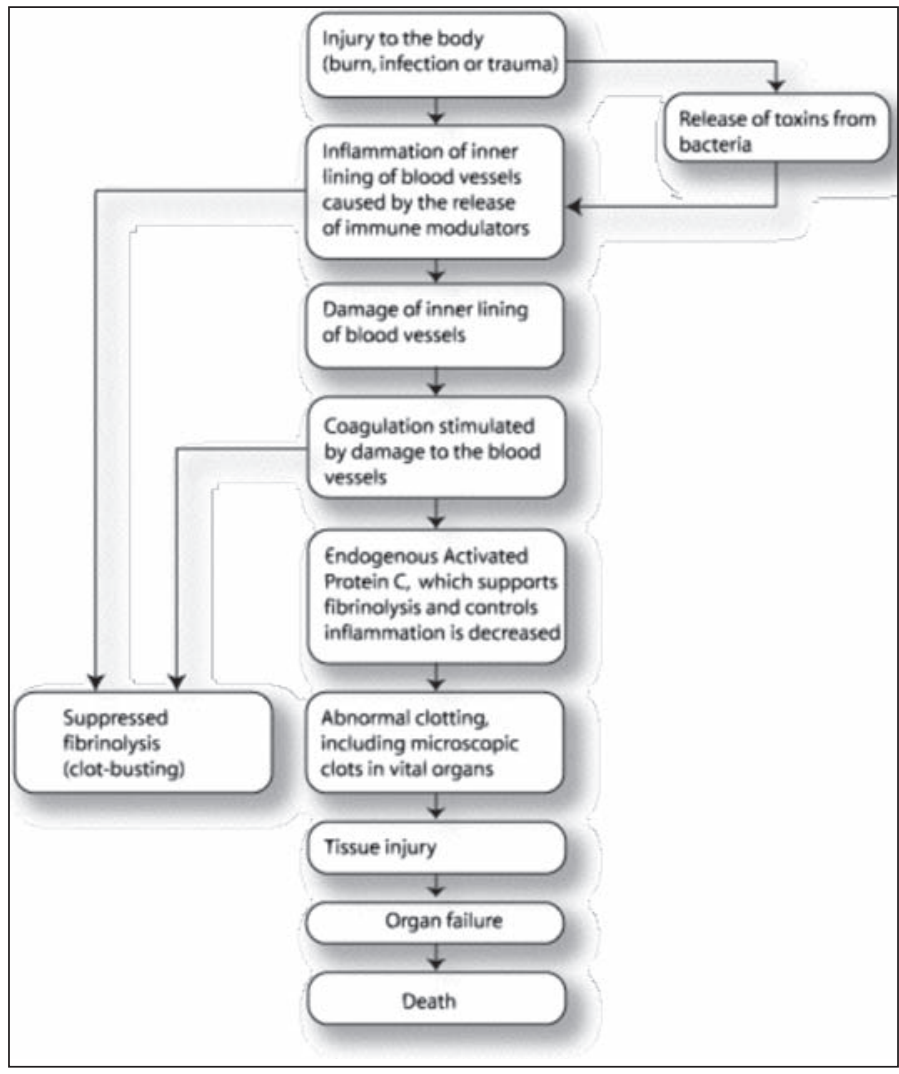

Figure 1: The Severe Sepsis Cascade (Lilly, 2003)

consciousness, tachypnea, jaundice, tachycardia, hypotension hypovolemia, oliguria and anuria (Ahrens and Vollman 2003).

\section{Treatment Interventions in Severe Sepsis}

Traditionally, treatment protocols for severe sepsis patients are targeted at stabilising the patient with symptomatic treatment. This involves fluid therapy and resuscitation and vasoactive medication. Ventilator supports secure optimal oxygenation by mechanical ventilation, and hemodynamic monitoring and goal directed therapy are needed, with mean arterial pressure $>65 \mathrm{mmHg}$ and $<95 \mathrm{mmHg}$, central venous pressure from $8-12 \mathrm{mmHg}$, and cardiac index $>2.5 \mathrm{l} / \mathrm{min} . / \mathrm{m}^{2}$. As the inflammatory focus and agent is often unknown, antibiotic therapy has a limited effect in the initial phase. Professional critical care nursing, in collaboration with treatment initiated by dedicated, specialised physicians, is required for safe and optimal treatment of the unstable, acute and critically ill septic shock patient.

\section{A NEW PARADIGM IN SEPTIC SHOCK TREATMENT?}

The nature of severe sepsis calls for aggressive treatment of symptoms. However, as this approach alone has shown to be inadequate, recent research has been directed at causal treatment beyond stabilising the patient. The focus has been set on reversing the progression of the devastating cascade of reactions illustrated in Figure 1. In the PROWESS trial, a randomised, double-blind, placebo-controlled multi-centre study, treatment with a 96 hour infusion (in the intervention arm) with drotrecogin alfa (activated; recombinant activated protein C) in adult patients with severe sepsis and multiple organ failure (Dhainaut et al. 2003) was introduced. 1271 patients from 164 medical centres were included.
The results were: significantly lowered observed 28 day mortality (7.4\%) with drug treatment than with placebo (26.5\% vs. $33.9 \%)$; cardiovascular and respiratory organ dysfunction resolved more rapidly over the first 7 days; and serious bleeding events were more frequent $(2.4 \%$ vs. $1.3 \%)$. Normal mortality rates in severe sepsis range from $30 \%$ to $50 \%$ (Angus 2001). The difference in serious bleeding rates was found to be clinically significant, but the overall benefit-risk profile was found to be favourable. In another study, the effects of drotrecogin alpha (activated; recombinant activated protein C) in 2786 patients in clinical trials and 3991 patients receiving the drug in commercial use were evaluated (Bernard et al. 2003). A significant reduction in mortality in severe sepsis patients was found to be persistent over multiple clinical trials. Bleeding incidents were found to be related to invasive procedures during the infusion period, but still slightly higher than in the control groups (between $2.1 \%$ and $2.8 \%$ vs. $2.0 \%$ ).

\section{Consequences for clinical use}

Activated protein $\mathrm{C}$ has been shown in multiple clinical trials to significantly reduce mortality in severe sepsis. Bleeding is a negative side effect. Since bleeding tends to be procedure related, it is suggested that the infusion of the compound is stopped two hours before the procedure to avoid adverse bleeding events. The drug can be administered 12 hours after major surgery.

The serious bleeding events are most frequent on day one of therapy, and then rapidly decline. Rapid improvement is key to survival in severe sepsis. The study data suggest that early intervention, as in myocardial infarction and stroke, and reduction of the time factor combined with aggressive treatment are essential for improved patient outcome. The drug Xigris ${ }^{\circledR}$ (drotrecogin alpha [activated]) from Eli Lilly and Company is the first and only therapy indicated for the treatment of severe sepsis. The drug modulates the coagulation cascade in several ways and, as a consequence, improves cardiovascular and respiratory function. The beneficial effects include control of excessive inflammation and blood clotting, reduction of inflammation, and reduction and removal of blood clots.

\section{Implications for critical care nurses}

Critical care nurses spend most of their time at the point of care. The attention given to the patient is proportional with the patient acuity. Critical care nurses are, in many cases, the first to observe the signs and symptoms related to development of severe sepsis. It is essential that knowledge about the disease, early symptoms, observation focus, and treatment intervention are well known to them. The patient outcome relies on appropriate, safe and timely care.

There are three important aspects to focus on. In the first phase, the early bedside recognition and problem identification of sepsis is essential. The second phase is the safe and timely administration of the drug therapy. Finally, the prevention of further complications and the protection against hospital acquired infections becomes a challenge and an ultimate goal.

In fact, severe sepsis patients challenge the critical care nurse's profession with their complex, unpredictable and diffuse disease. A structured approach is needed, and best practice needs to be developed on evidence-based knowledge.

According to Lilly, Xigris ${ }^{\circledR}$ has proved its position as the only weapon directed at fighting the causes of severe sepsis. Patient 
outcome is significantly improved, and is documented in multiple clinical trials. Still, there may be more improvements to achieve as experience with the new drug is gained. Critical care nurses must follow the development carefully, and use this progress to improve their strategies and professional thinking.

\section{DISCUSSION}

Severe acute disease in general requires the right treatment performed with correct timing. This means that the right people have to be available at the right time, to carry out the right intervention for the symptoms presented by the patient. Several studies have shown that structured organisation of treatment and simple interventions can improve patient outcome. One example was a randomised study with the introduction of six hours of early goal directed therapy to optimise balance between oxygen delivery and oxygen demand, and identify risk for cardiac collapse or standard therapy for patients $(n=263)$ with severe sepsis or septic shock. The study results showed significant benefits in patient outcome with a reduction of in-hospital mortality (30.5\% vs. $46.5 \%$; Rivers et al. 2001). Sepsis causes a diagnostic dilemma due to a diffuse and unpredictable onset. The results from a randomised study by Van Den Berghe et al. (2001) showed that rigid control and systematic regulation of blood glucose led to a reduction in overall in-hospital mortality by as much as $34 \%$. A substantial North American study published in JAMA shows that each additional patient per nurse was associated with a $7 \%$ increase in risk of dying within 30 days of admission and a $7 \%$ increase risk for complications during the same period (Aiken et al. 2002). Another study showed that highdensity physician staffing, meaning daily consultations, resulted in a reduction in hospital mortality and length of stay (Pronovost 2002). The studies mentioned above support the importance of redefining the $\mathrm{ICU}$, from places to systems of best practice care, in terms of doing the right things properly.

A choice between weapons is always an advantage. Severe sepsis is likely to become an increasing problem in the ICU population. According to Lilly, the development of Xigris ${ }^{\circledR}$ represents an important step forward. Xigris ${ }^{\circledR}$ is a genetically engineered version of the human activated protein $\mathrm{C}$ molecule. This naturally occurring protein in the body helps balance many of the major forces behind sepsis, including coagulation (blood clotting) and suppression of fibrinolysis (clot-busting). Lilly claims to have taken a leading position in this field and to have provided the only clinical weapon to fight severe sepsis.

In an article in The Wall Street Journal, criticism is raised against Lilly's campaign to promote increased use of Xigris (Regalado 2003). According to this article, some analysts were predicting sales would reach $\$ 1$ billion a year, while the total US sales in 2002 were only $\$ 100$ million. With a cost of $\$ 6,800$ per treatment (in the US), many physicians find it hard to justify the use of the drug. Regalado also points out the ethical dilemma with treatment only available for patients who can afford the cost of the drug, excluding those who cannot pay. The number needed to treat (NNT) is eight to save one life (Ahrens and Vollman 2003). The cost to save one life in this perspective is $\$ 54,400$, a substantial amount of money in many ICUs with limited economic resources. Thus many hospitals have chosen not to recommend the use of Xigris in their routine treatment of severe sepsis patients. The reasons are insufficient documentation, the fact that Xigris' effect on different subgroups of patients still remains to be clarified and the high costs.

As the experience with Xigris grows and more detailed information of its limits and benefits are collected, the final position of the drug will be more clearly defined in the future. As the studies referred to in this article show, relatively simple interventions can give very good and statistically significant results in patient outcome. My impression is that Xigris has not yet proved to be the new gold standard in the treatment of patients with severe sepsis.

In conclusion, early intervention and a systematic approach have shown to be essential for the outcome of severe sepsis patients. Critical care nurses are important contributors and participants in treatment teams for severe sepsis patients. Critical care nurses need to update their knowledge and follow the development in therapeutic interventions carefully to contribute to improve the outcome for patients with severe sepsis as much as possible.

\section{Postscript}

For further information about sepsis and its treatment visit http:// www.sepsis.com/ or download the free booklet Understanding Sepsis from the International Sepsis Forum: http://www.sepsisforum.org/

\section{REFERENCES}

Aiken LH, Clarke SP, Sloane DM, Sochalski J \& Silber JH. (2002) Hospital nurse staffing and patient mortality, nurse burnout and job dissatisfaction. JAMA, 288 (16): 1987-1993.

Ahrens T \& Vollman K. (2003) Severe Sepsis Management Are We Doing Enough? Critical Care Nurse (Supplement) 23 (5): 2-15.

Angus DC, Linde-Zwirble WT, Lidicker J, Clermont G, Carcillo J \& Pinsky MR. (2001) Epidemiology of severe sepsis in the United States: analysis of incidence, outcome and associated costs of care. Critical Care Medicine 29 (7): 1303-1310.

Bernard GR, Macias WL, Joyce DE, Williams MD, Bailey J \& Vincent JL. (2003) Safety assessment of drotrecogin alfa (activated) in the treatment of adult patients with severe sepsis. Critical Care 7 (2): 155-163.

Bone RC, Balk RA, Cerra FB, Dellinger RP, Fein AM, Knaus WA, Schein RM \& Sibbald WJ. (1992) Definitions for sepsis and organ failure and guidelines for the use of innovative therapies in sepsis. Chest 101 (6): 1644-1655.

Davies A, Green C, Hutton J \& Chinn C. (2001) Severe sepsis and septic shock: a European estimate of the cost of illness in ICUs. Abstract presented at European Society of Intensive Care Medicine, October 2001.

Dhainaut JF, Laterre PF, Janes JM, Bernard GR, Artigas A, Bakker J,

Riess H, Basson BR Charpentier J, Utterback BG \& Vincent JL. (2003) Drotrecogin alfa (activated) in the treatment of severe sepsis patients with multiple-organ dysfunction: data from the PROWESS trial. Intensive Care Medicine 29 (6): 894-903.

Lilly. (2003) The Severe Sepsis Cascade. Press Briefing Information Kit. Distributed at the 16th Annual Congress of the European Society of Intensive Care Medicine, October 2003, Amsterdam, The Netherlands.

Pronovost JP, Angus DC, Dorman T, Robinson KA, Dremsizov TT \& Young TL. Physician staffing patterns and clinical outcomes in critically ill patients: a systematic review. JAMA, 288 (17): 2151-2162.

Regalado A. (2003) To sell pricy drug, Lilly fuels a debate over rationing. Wall Street Journal (East Ed) Sept 18: A1, A2.

Rivers E, Ngyen B, Havstad S, Ressler J, Muzzin A, Knoblich B, Petterson E, Tomlanovich M. (2001) Early goal-directed therapy in the treatment of 
severe sepsis and septic shock. The New England Journal of Medicine 345 (19): 1368-1377.

Van Den Berghe G, Wouters P, Weekers F, Verwaest C, Bruyninckx F,
Schetz M, Vlasselaers D, Ferdinande P, Lauwers P \& Boullion R. (2001) Intensive insulin therapy in critically ill patients. The New England Journal of Medicine 345 (19): 1359-1367. 